\title{
A METHODOLOGY FOR DECISION SUPPORT FOR IMPLEMENTATION OF CLOUD COMPUTING IT SERVICES
}

\author{
DOI: 10.12776/QIP.V18I1.275
}

ADELA TUŠANOVÁ, JÁN PARALIČ

Received 11 February 2014, Revised 3 June 2014, Accepted 26 June 2014

\section{INTRODUCTION}

Cloud computing is nowadays very popular business and also scientific domain. Cloud solutions are presented by their providers as the best IT solutions despite initial non confidence in safety. Especially large IT providers keep pace with new technologies, who invest huge amount of money in research and development. On the contrary, small and medium-sized IT companies are trying to keep up with competitors and to catch up with this trend. More and more software developers deal with the question to develop or do not develop their software solutions for cloud (and thus in the form of Software as a Service - SaaS). They still lack some kind of coherent methodology that would adequately support their decision in this matter.

The transition to cloud computing can be viewed from two perspectives - the transition from the customer perspective and the transition from the perspective of the supplier. The transition to cloud computing from the customer's perspective means the comprehensive analysis of the business environment and its needs. The aim of the analysis is to determine the current situation in the company and identify areas where cloud computing could improve the situation and how. To perform such an analysis deep knowledge of the analysed topic is necessary. Companies do not have such a deep knowledge, because cloud computing is a relatively new technology. Therefore we can find various research groups or even cloud providers involved in the development of different analyses (Shanmugasundaram and Hamid, 2011), (Tušanová and Paralič, 2012).

The transition to cloud computing from the perspective of the supplier means to become a provider of cloud services, whether at IaaS (Infrastructure as a Service), PaaS (Platform as a Service), or SaaS. Providing IaaS requires a high initial cost, since it is necessary to build data centres. Development of PaaS and SaaS solutions requires particular knowledge of the new architecture and new 
business model (Tušanová and Paralič, 2013). It is important to note that the actual provider of solutions can also be in the role of the customer, in case when part of the provided solution is outsourced.

The authors, who are dedicated to transition to cloud computing have different approaches. First, it is a different view of the supplier and the customer, but mainly it is the difference in the perception of the problem itself. While some authors understood transition as a purely technical problem (Bibi, Katsaros and Bozanis, 2010), (Leymann et al., 2011), others view purely economic or strategic problem (Klems, Nimis and Tai, 2009), (Misra and Mondal, 2011), (Saripalli and Pingali, 2011). Some studies aim to formalize the problem but in the end they do not solve it (Leymann et al., 2011), and on contrary the others have application approach and want to offer tools that facilitate problem solving (Menzel et al., 2011; Khajeh-hosseini et al., 2011; Shanmugasundaram and Hamid, 2011).

Therefore we decided to propose and evaluate such a methodology, which would not deal only with selected part of decision problem, but will help to make complex decision based on couple of analyses.

\section{METHODOLOGY}

The proposed methodology is based on an analysis of works dedicated to the transition to cloud computing. Based on a careful analysis of available works dealing with the transition to cloud computing were identified essential elements of decision-making. Identification of the gaps in the available works was the next step of our analyses. After evaluation of identified essential elements and gaps we have decided to focus the research on the transition to SaaS model from the perspective of the supplier (the Independent Software Vendor, ISV). Each factor affecting the decision was analysed, reviewed and, if necessary, possible improvements have been proposed. Subsequently, the synthesis of all analysed factors established the proposed methodology. To verify the proposed methodology case study as the one of the most popular qualitative scientific methods was chosen and performed on four small IT companies.

\section{PROPOSED METHODOLOGY FOR DECISION SUPPORT}

The result of our research is the methodology for decision support in the transition to the cloud computing SaaS model, consisting of nine steps, see Figure 1. 


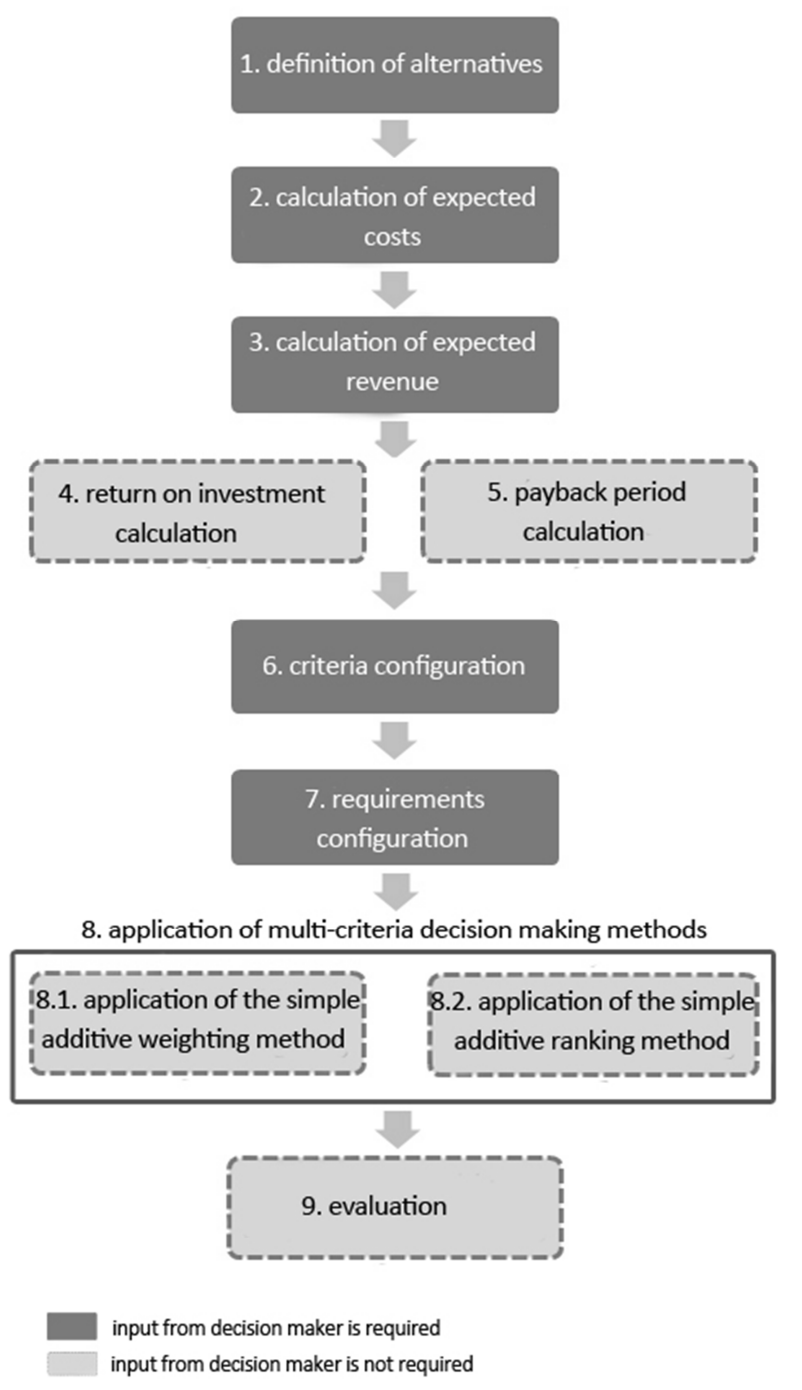

Figure 1 - Proposed methodology for decision support

\subsection{Definition of alternatives}

The first step of the proposed methodology is the selection of alternatives that the person responsible for strategic decision-making in the company (the decision maker) wants to consider and compare them. We suggest following alternatives for the methodology:

A1. SaaP, Software as a Product - software, which is typically sold with infinite license or other types of licenses. Infrastructure can be ensured by the customer or the supplier can deliver it together with the software solution. 
A2. SaaS solution, where ISV ensures his own data centre as well as providing a platform and the application itself,

A3. SaaS solutions, where infrastructure is ensured by 3rd part provider and ISV ensures platform and the application itself,

A4. SaaS solutions, where infrastructure and platform are ensured by 3rd part provider and ISV ensures only the application itself,

A5. SaaS solutions, which is completely outsourced by 3rd part provider.

Selection of alternatives is an important input for further steps.

\subsection{Calculation of expected costs}

The important part of the proposed methodology is to analyse the cost of all alternatives considered. Analysis of the total cost is addressed in the method Total Cost of Service/Software Delivery - TCSD (York, 2013), which reflects the full cost of service or software delivery. The key is to identify the relevant cost items as cost items vary depending on problem solved and therefore are not exactly defined. The result of our research is therefore the proposal of a taxonomy of costs. Designed cost structure is based on an analysis of existing resources, the inclusion of new identified cost items and assignment these items to alternatives identified in previous step. Brief description and the method of calculation of each item is also provided.

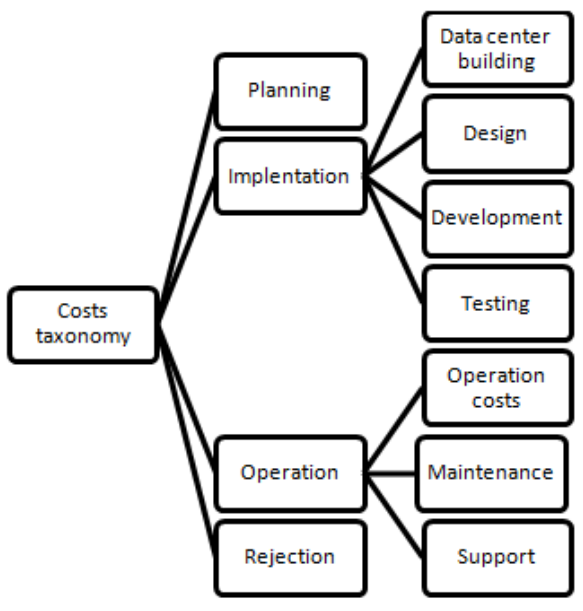

Figure 2 - Proposed cost taxonomy

\subsection{Calculation of expected revenue}

One of the main goals of any company is maximize profit which means gain the highest possible revenue at minimum cost. The estimated revenue from the sale of the software or service delivery is therefore a key indicator. In many papers the authors present a simple estimate of the revenue based on the number of 
software licenses sold. In the case of SaaS, however, revenue is not so easily predictable, and the calculation is made using specific metrics. Moreover, the company's revenue consists of complementary services and support. The result is therefore the identification of streams of income arising from both the software product as well as the software as a service (see Table 1). Brief description and the method of calculation of each revenue stream is also output of our research.

Table 1 - Proposed revenue taxonomy

\begin{tabular}{|l|c|c|c|}
\hline Revenue stream & $\begin{array}{c}\text { Recurring } \\
\text { Revenue }\end{array}$ & $\begin{array}{c}\text { SaaP } \\
\text { (alternative A1) }\end{array}$ & $\begin{array}{c}\text { SaaS (alternative } \\
\text { A2) }\end{array}$ \\
\hline Subscription & yes & - & $\mathrm{x}$ \\
\hline Pay par use & yes & - & x \\
\hline Perpetual license & no & x & - \\
\hline Maintenance & yes & x & - \\
\hline Implementation & no & x & x \\
\hline Trainings and support & no & x & x \\
\hline Rent Datacenter & yes & - & - \\
\hline Advertisement & yes & & \\
\hline
\end{tabular}

\subsection{Calculation of Return on investment}

Return of Investment - ROI (Phillips, 1997) expresses the ratio of earnings before interest and repayment of taxes on capital employed (in \%). ROI is one of the most widely watched indicators of the investment decision and therefore is included in proposed methodology as one of the financial criteria. Final value of ROI is calculated for each alternative while costs and revenue from previous steps are used as input for calculation.

\subsection{Calculation of Payback period}

Payback period (Nekvasil, 2008) is the period over which revenue stream (cash flow) will equal to the initial cost of the investment. In other words, answers the question: How long it takes to get back the money invested? It is mainly used for investment decisions. The longer the investment return, the riskier it is for us. The payback period is one of the simplest and most widely used indicator and therefore is included in proposed methodology as one of the financial criteria. Similar to ROI, costs and revenue from previous steps are used as input for calculation of payback period for each alternative.

\subsection{Criteria configuration}

Besides the mentioned financial indicators the decision maker decides on the basis of other criteria. Criterion is understood as a specific objective measure by 
which we judge an object, an alternative. The partial result of our research is therefore the taxonomy of criteria, which was identified by analysis of the available literature. For each criterion a brief description, example, type as well as possible values are presented. Overview of taxonomy of criteria is given in Table 2. Mandatory criteria are marked with the * symbol.

Table 2 - Taxonomy of criteria

\begin{tabular}{l|l|l|l} 
Strategic & Financial & Technical & Risk \\
\hline $\begin{array}{l}\text { S_K1 Competitive } \\
\text { advantage / value } \\
\text { added }\end{array}$ & $\begin{array}{l}\text { F_K1 Estimated costs } \\
*\end{array}$ & $\begin{array}{l}\text { T_K1 Number of } \\
\text { developed software } \\
\text { versions }\end{array}$ & $\begin{array}{l}\text { R_K1 Cannibalization } \\
\text { of other solutions }\end{array}$ \\
\hline $\begin{array}{l}\text { S_K2 Knowledge of } \\
\text { user behavior and use } \\
\text { of an application }\end{array}$ & $\begin{array}{l}\text { F_K2 Estimated } \\
\text { revenue * }\end{array}$ & T_K2 Scalability & $\begin{array}{l}\text { R_K2 Breach of } \\
\text { contract/SLA }\end{array}$ \\
\hline $\begin{array}{l}\text { S_K3 Acquiring new } \\
\text { customers / access to } \\
\text { new markets }\end{array}$ & F_K3 ROI & $\begin{array}{l}\text { T_K3 Control over } \\
\text { supplied } \\
\text { service/product }\end{array}$ & $\begin{array}{l}\text { R_K3 Non- } \\
\text { compliance }\end{array}$ \\
\hline $\begin{array}{l}\text { S_K4 Speed of } \\
\text { product /service on } \\
\text { the market delivery } *\end{array}$ & F_K4 Payback period & $\begin{array}{l}\text { T_K4 Need for high } \\
\text { data security }\end{array}$ & $\begin{array}{l}\text { R_K4 Wrong business } \\
\text { model }\end{array}$ \\
\hline $\begin{array}{l}\text { S_K5 Company } \\
\text { image }\end{array}$ & & $\begin{array}{l}\text { T_K5 Integration with } \\
\text { other information } \\
\text { systems }\end{array}$ & $\begin{array}{l}\text { R_K5 Lock-in of data } \\
\text { and application }\end{array}$ \\
\hline $\begin{array}{l}\text { S_K6 Support and } \\
\text { customer relationship } \\
\text { quality }\end{array}$ & & $\begin{array}{l}\text { T_K6 Necessity to } \\
\text { ensure supporting } \\
\text { tools }\end{array}$ & $\begin{array}{l}\text { R_K6 Extensive } \\
\text { changes in the } \\
\text { organization }\end{array}$ \\
\hline $\begin{array}{l}\text { S_K7 Predictable } \\
\text { Income }\end{array}$ & $\begin{array}{l}\text { T_K7 Technological } \\
\text { innovations }\end{array}$ & $\begin{array}{l}\text { R_K7 Loss of income } \\
\text { due to illegally } \\
\text { distributed solution }\end{array}$ \\
& & &
\end{tabular}

The goal is not to consider all of identified criteria, but to point out all possible aspects which influence the decision. Therefore relevant criteria for considered scenario are selected by decision maker in first step. In next step, weights of selected criteria are determined and ultimately the value of the usefulness of each criterion is determined.

\subsection{Requirements configuration}

Requirement is defined as the minimum or maximum value of the selected criterion (or several criteria). The goal of the requirements is to filter out those alternatives that are not feasible in a given scenario. In proposed methodology seven requirements are defined, formulated as questions over the seven criteria maximum delivery time of the product / service to the market, maximum initial cost, maximum annual operating costs, minimum annual income, minimum 
return on investment, maximum payback period and minimal control over the delivered solution.

\subsection{Application of the methods of multi-criteria decision making}

In this step multi-criteria decision making methods are applied. For the proposed methodology methods SAW (Simple Additive Weighting) (Yoon and Hwang, 1995), and SAR (Simple Additive Ranking) (Ocelíková, 2011) were chosen, since according to (Ocelíková, Zolotová and Landryová, 2005), on the same set of alternatives and criteria, both methods give the same result. Both methods evaluate selected criteria over the alternatives and rank them from most suitable to least suitable, giving a decision maker the answer to the question which alternative is most suitable for a given scenario.

\subsection{Evaluation}

In this step, obtained results for a given scenario are interpreted. A briefly summarized available alternatives are provided first. Then excluded alternatives and the reasons for their exclusion are summarized. Follows the most appropriate alternative and other alternatives, sorted by their scores resulted from the evaluation processes by means of SAR and SAW methods (calculated for the set of not excluded alternatives). Valuable part of the evaluation is a detailed assessment of financial indicators TCSD, revenue, ROI and payback period, together with a graphical interpretation.

\section{CASE STUDY I}

The first case study was realized in cooperation with an international IT company which has the branch in Kosice, Slovakia. The company did not wish to be named therefore we will refer to it as ITFA (IT company A) in this paper. Analysed software SW1 is an internal system for managing training (the learning management system). This software helps company's employees manage their own trainings and other activities related to personal growth. This case study was atypical in two aspects - analysis of the software was focused only on cost analysis, as this is the most demanding part of the methodology and there was one more alternative examined - so-called in-house solution. In-house solution is a solution where developer of an application provides it to its customers, i.e. branch in Kosice provides SW1 to other branches worldwide. Each branch however takes care of the infrastructure on its own.

Results of the cost analysis have been implemented in the form of an Excel file, which enables quick calculation of total costs for all alternatives considered and their subsequent comparison. The cost analysis was also supplemented by assessment of the advantages, disadvantages and risks from the perspective of the supplier and the customer. The case study has brought one of the important knowledge, that some cost items is difficult to quantify. Therefore, it was necessary to refine the proposed methodology. 


\section{IMPROVEMENT OF THE PROPOSED METHODOLOGY}

As the quantification of certain cost items is a difficult task, we have decided to develop a procedure inside our decision support system, which leads user to properly identify the final cost. The main goal of the proposed procedure is to determine the estimated costs of cost item consultation with experts, based on the responses from the users. As a first step, we analysed the available literature to identify key experts, who are important in planning phase and assigned them to defined alternatives. Costs of consultations with experts are then calculated as the sum of the cost of all consultants pertaining to the selected alternative, where the cost per consultant is calculated as required number of hours for consultations multiplied by his hourly rate.

Defining the number of required hours as well as the average gross hourly wage of each expert is a challenging task. Since the number of necessary consultation hours is a vague question, it is necessary to support the decision maker in some way to define the appropriate value. The basic principle of the proposed procedure how to define the number of required hours and gross hourly wage for $\mathrm{x}^{\text {th }}$ expert is shown on Figure 3. The first step is to estimate the gross hourly wages which can be defined in two ways: If the decision maker/the company has its own internal or external consultant, known gross hourly rate will be applied; If the decision maker/the company does not have any consultant, then the value from the knowledge base will be applied.

The initial gross hourly wages of each consultant which is based on research on the Internet is defined at the beginning in the knowledge base. Initial values are subsequently iteratively modified by arithmetic average gross hourly wages obtained from companies which used the system.

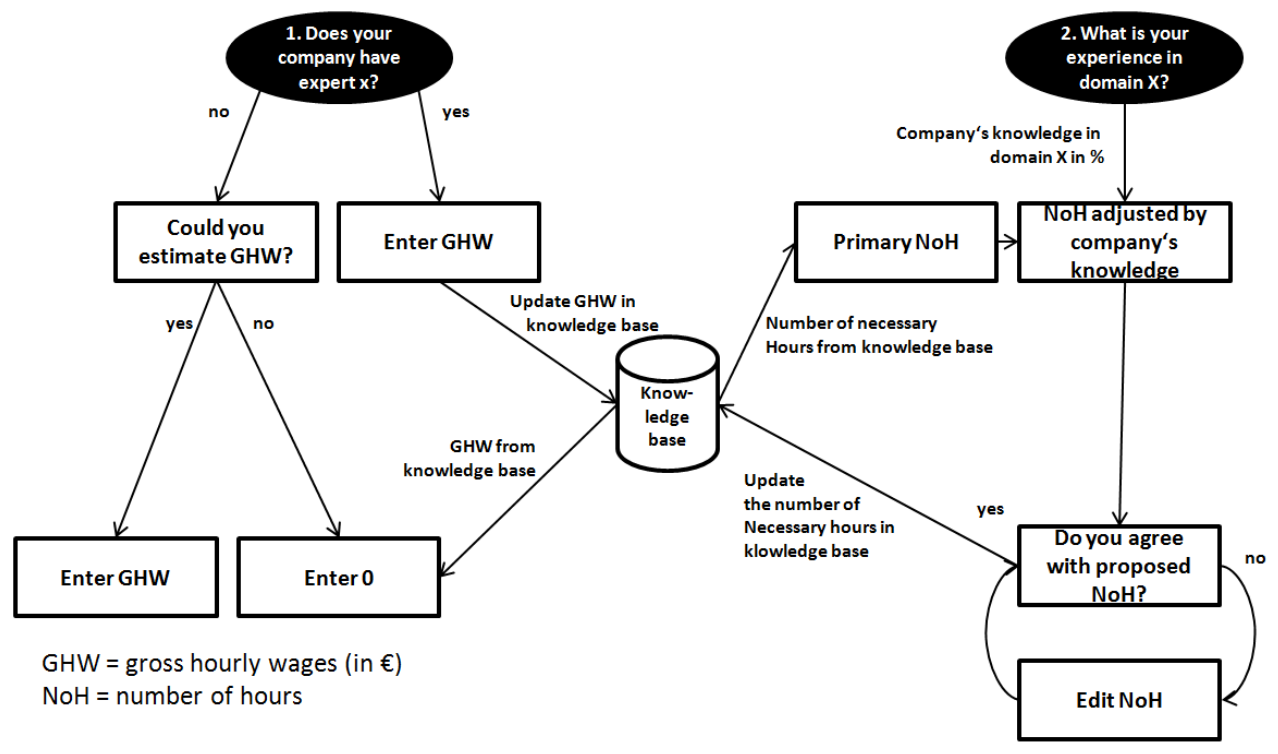

Figure 3 - The main principle of proposed supporting procedure 
In the next step it is necessary to estimate the number of hours required to consult with individual expert, what actually depends on knowledge the company has. We have defined following range of values to estimate more accurate values:

- $0 \% \Rightarrow$ Considered consultation is not needed (the company has experience in the field or the result of the consultation is already finished),

- $50 \% \Rightarrow$ A verification consultation (the company has experience in the field, but needs a check with experienced experts),

- $100 \% \Rightarrow$ A simple consultation (the company has already heard about the field and has some experiences, but it needs professional help with preparing a plan / contract / analysis / project etc.),

- $150 \% \Rightarrow$ An extensive consultation (the company has already heard about the field, but has no direct experiences and therefore needs extensive help to develop a plan / contract / analysis / project etc.),

- $200 \% \Rightarrow$ A comprehensive consultation (the company has never heard about the field and needs to explain it in the details and fully develop a plan / contract / analysis / project etc.).

The system raises questions to decision-maker over defined range, thereby indirectly evaluates the level of knowledge in the considered field. Subsequently the evaluated level of knowledge is multiplied by the number of estimated hours. As well as in the case of gross hourly wages, there is also the initial value defined in the knowledge base. After the calculation of the estimated hours a decision maker is able to adjust the number of hours if (s)he does not agree with the estimation made by the system. All of the values gained from decision makers are saved in the knowledge base and already saved values are adjusted by arithmetic average of all values and saved.

As the interaction with decision maker and creation of knowledge base is necessary, the proposed methodology has been implemented as a web application and is available at http://www.adelatusanova.sk/dizertacka. Important part of the application are tips on useful models and tools to help users better understand the issue. There are also warnings and recommendations included in some cost items descriptions, which helps decision makers to better understand these cost and their calculations. The control mechanism is also implemented in the system, so based on simple rules, for example, alternatives for which zero cost or zero income was specified are automatically excluded.

\section{CASE STUDY II}

The second case study was realized in cooperation with the company GX Solutions. GX Solutions provides products and services to companies that operate vehicle fleet and any type of transport. Analysed software TDM is focused on monitoring of vehicles, fuel and logistics. Using our decision support system, we have analysed existing SaaP solution and the possibility to move the 
application to the SaaS model. As the costs related to data centre was not entered by decision maker, alternative A2 was automatically excluded from the analysis. After the all analyses of all entered data, the existing alternative A1 - SaaP was evaluated as the best alternative. SaaS alternatives are unsuitable because TDM is the software which requires to be tightly integrated with other software and often needs substantial adaptation to the needs of the customer. The unsuitability of SaaS solutions is also shown by the financial indicators, where the ROI for possible move to all the SaaS alternatives (A3 to A5) is negative and the payback period exceeds five years.

\section{CASE STUDY III}

The third case study was realized in cooperation with the start-up company that does not wish to be named, therefore, it is further referred as ITFB (IT company B). The main ITFB's goal is to create an application that will present businesses such as discos, hotels, restaurants, bars etc. all around the world using video business cards in several languages. The company right at the beginning excluded an alternative of ensuring own data centre (A2). ITFB also rejected outsourcing solution (A5), because there are two programmers in the team which are enthusiastic in the final application. Finally alternatives A3 - outsourced infrastructure and A4 - outsourced infrastructure and platform were analysed. Alternative A1 - traditional software solution has been excluded, since the company does not have this solution currently and does not even considering it. After analyses of all input data alternative A3 - SaaS - outsourced infrastructure was evaluated by the propose methodology as the best one.

\section{CASE STUDY IV}

The last case study was created in cooperation with the company Utilis. We have analysed software product DEIMOS - hotel reservation system, which allows bookings and data processing. Alternative A2 - data centre development was excluded at the beginning, as the Utilis is a small company and has only three employees. After the analyses of all data alternative A1 - traditional and already existing software solution was evaluated as the best one. Alternatives A3 outsourced infrastructure and A4 - outsourced infrastructure and platform were evaluated as inappropriate, because the payback period was longer than 3 years. In this case, SaaS solution is not the best for company Utilis.

\section{CONCLUSION}

The result of our research is the proposed methodology for decision support for the implementation of cloud computing IT services. At be beginning, we have identified all the possible alternatives. Then, we have designed targeted costs and revenue taxonomies, which have been identified by analysing all available 
literature. The result is also a well-defined list of criteria that influence the decision of a particular alternative. Proposed methodology was implemented as a web application and verified via four case studies. First case study helped us to find the gap in proposed methodology. Also, we identified advantages and disadvantages of all alternatives from customer's and provider's point of view. This output was very helpful for ITFA. Our methodology also helped to verify that the current SaaP solution is the best alternative for two companies - GX Solutions and Utilis. This finding is very valuable for both of them; it helped them to avoid the loose of energy to something not worth enough. The last case study helped the start-up company to make the decision regarding the best outsourcing model. The very important part of our research is also proposed decision making system described in chapter 5. Proposed decision support systems can be expanded in the future to support not only the single cost item, but the whole alternative or even alternatives to each other. Verification of the proposed methodology through case studies confirms the direct use of the proposed methodology in practice.

\section{ACKNOWLEDGEMENT}

This publication is the result of the Project implementation: University Science Park TECHNICOM for Innovation Applications Supported by Knowledge Technology, ITMS: 26220220182, supported by the Research \& Development Operational Programme funded by the ERDF (50\%) and by the Scientific Grant Agency of the Ministry of Education, Science, Research and Sport of the Slovak Republic under the grant No. 1/1147/12 (50\%). 


\section{REFERENCES}

Bibi, S., Katsaros, D. and Bozanis, P., 2010. Application Development: Fly to the Clouds or Stay In-house? In: Enabling Technologies: Infrastructures for Collaborative Enterprises (WETICE), 19th IEEE International Workshop, pp.60-65.

Khajeh-hosseini, A., Sommerville, I., Bogaerts, J. and Teregowda, P., 2011. Decision support tools for cloud migration in the enterprise. In: Cloud Computing (CLOUD), IEEE International Conference, pp. 541-548.

Klems, M., Nimis, J. and Tai, S., 2009. Do clouds compute? A framework for estimating the value of cloud computing. In: Designing E-Business Systems. Markets, Services, and Networks, Springer Berlin Heidelberg, pp. 110-123.

Leymann, F., Fehling, C., Mietzner, R., Nowak, A. and Dustdar, S., 2011, Moving applications to the cloud: An approach based on application model enrichment. In: International Journal of Cooperative Information Systems, Vol. 20, No. 03, pp. 307-356.

Menzel, M., Schönherr, M., Nimis, J. and Tai, S. 2011), $\left(\mathrm{MC}^{2}\right)^{2}$ : A Generic Decision-Making Framework and its Application to Cloud Computing. In: arXiv preprint arXiv:1112.1851.

Misra, Ch. and Mondal, A, 2011. Identification of a company's suitability for the adoption of cloud computing and modelling its corresponding Return on Investment. In: Mathematical and Computer Modelling, Vol. 53, No. 3, pp. 504521.

Nekvasil, M., 2008. Možnosti hodnocení efektivity investic do IT. Systémová integrace, 2008. Česká společnost pro systémovou integraci, Praha

Ocelíková, E., 2011. Viackriteriálne rozhodovanie. Košice: Technická univerzita.

Ocelíková, E., Zolotová I. and Landryová, L., 2005. Multi-criteria decision making methods $=$ Metódy multikriteriálneho rozhodovania. In: Sborník vědeckých prací Vysoké školy báňské - Technické univerzity Ostrava, Ostrava: VŠB-TU, 2005, pp. 179-186.

Phillips, J.J., 1997. Return on investment. Houston, Tex.: Gulf Pub. Co.

Saripalli, P. and Pingali, G., 2011, MADMAC: Multiple Attribute Decision Methodology for Adoption of Clouds. In: Cloud Computing (CLOUD) 2011 IEEE International Conference, pp. 316-323.

Shanmugasundaram S. and Hamid, T., 2011. IBM: Guiding the cloud application decision with the IBM Cloud Transformation Advisor. [online] Available at: $<$ http://www.idgconnect.com/view_abstract/12829/guiding-cloud-applicationdecision-ibm-cloud-transformation-advisor> [Accessed 25. Oktober 2013]. 
Tušanová, A. and Paralič, J., 2012. A comprehensive framework for software as a service adoption. In: proceeding of the International Conference on ICT Management for Global Competitiveness and Economic Growth in Emerging Economies, Wroclaw, Poland, 2012, pp. 347-356.

Tušanová, A. and Paralič, J., 2013. Decision support system for Software as a Service applications. In: LINDI 2013: 5th IEEE International Symposium on Logistics and Industrial Informatics Proceedings, Wildau, Germany, 2013, pp. $147-152$.

York J., 2013. SaaS TCO : The Mirror Image of Total Cost of Service. [online] Available at: <http://chaotic-flow.com/saas-tco-the-mirror-image-of-total-costof-service/?show=comments\#comments $>$ [Accessed 7. September 2013]

Yoon, P. and Hwang, Ch., 1995. Multiple attribute decision making: an introduction. Newbury Park, Ca: Sage Publications, Inc. 


\section{ABOUT THE AUTHOR}

Ing. Adela Tušanová, PhD. - Technical University of Košice, Faculty of Electrical Engineering and Informatics, Letná 9, 040 00, Košice, Slovakia, e-mail: adela.tusanova@tuke.sk.

prof. Ing. Ján Paralič, PhD. - Professor, Technical University of Košice, Faculty of Electrical Engineering and Informatics, Letná 9, 040 00, Košice, Slovakia, e-mail: jan.paralic@tuke.sk. 